\title{
Bor Nanoparçacıklarının Doğal Taşınımla Isı Transferinde Nanoakışkan Olarak Kullanımının İncelenmesi ve Karşılaştırılması
}

\author{
Investigation and Comparison of Usage of Boron \\ Nanoparticles as Nanofluid in Natural Convection Heat \\ Transfer
}

\author{
Birol Şahin ${ }^{*} \bullet$ \\ ${ }^{1}$ Recep Tayyip Erdoğan Üniversitesi Mühendislik ve Mimarlık Fakültesi Makine Mühendisliği Bölümü, Rize, TÜRKiYE \\ Sorumlu Yazar / Corresponding Author*: birol.sahin@erdogan.edu.tr

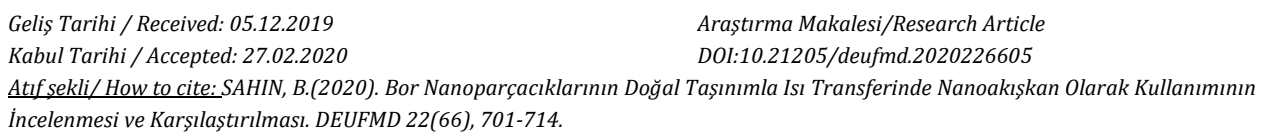

Gelișen teknolojiyle birlikte kendine daha fazla uygulama alanı bulan ve dünya üzerindeki rezervlerin büyük bir çoğunluğu ülkemizde bulunan bor elementi aynı zamanda stratejik bir öneme de sahiptir. Bu nedenle bor elementinin ısı transferi açısından etkinliğini belirlemek amacıyla çoğu ısı transferi uygulamasında akışkan olarak kullanılan su yerine, içerisine belirli hacimsel oranlarda bor nanoparçacıkları katılan nanoakışkan kullanılmıştır. Ele alınan problem geometrisi kare kesitli olup tamamen nanoakıșkan ile doludur. Bir düșey duvarından ısıtılan, diğer düșey duvarından soğutulan kapalı ortamda doğal taşınım ile gerçekleşen ısı transferi analiz edilmiştir. Bu amaçla geliştirilen ve içerisinde kaldırma kuvveti etkilerini de barındıran Boussinesq yaklaşımına göre elde edilen eşitlikler SIMPLE algoritmasına göre iteratif olarak çözülmüştür. Rayleigh sayısının $10^{4}-10^{6}$ aralığında yapılan çalışmada nanoparçacık hacimsel karışım oranı ise \% 0, 2 ve 4 şeklinde değişmektedir. Ana akışkan olarak kullanılan su için Prandtl sayısı 6.2 değerini almıştır. Rayleigh sayısı ve hacimsel karışım oranına bağlı olarak bor nanoparçacık için elde edilen sonuçlar, nanoparçacık olarak bakır veya alüminyum oksit kullanılması durumundakilerle karşılaştırılmıştır. Bor nanoparçacık kullanımında hacimsel karışım oranının artmasıyla ısı transferinin \% 14 oranında arttığı ve ısı aktarımının diğer nanoparçacıkların kullanıldığı durumlardakinden daha yüksek olduğu gözlenmiştir.

Anahtar Kelimeler: Bor nanoparçacık, Doğal taşınım, Hacimsel karışım oranı, Kare ortam, Nanoakışkan.

\section{Abstract}

The boron element, which finds itself in more application areas with developing technology and whose most of the world's reserves are located in our country, also has a strategic importance. For this reason, in order to determine the efficiency of boron element in terms of heat transfer, in most of the heat transfer applications nanofluid which has boron nanoparticles in certain volumetric fractions are used to replace the water used as fluid. The geometry of the problem is square and completely filled with nanofluid. Heat transfer values were determined by natural convection in the enclosure which was heated by a vertical wall and cooled from the other vertical wall. For this purpose, the equations obtained according to the Boussinesq approach, which contains the effects of buoyancy, were solved iteratively according to the SIMPLE algorithm. In the study of Rayleigh number between 104-106, nanoparticle volumetric fraction varies between 0,2 and $4 \%$. The Prandtl number for water 
used as base fluid is 6.2. The obtained results are presented for boron nanoparticle based on Rayleigh number and volumetric fraction and compared with those in which copper or aluminium oxide is used as the nanoparticle. In the use of boron nanoparticles, it was found that the heat transfer increased by $14 \%$ with increasing volumetric fractions and higher heat transfer occurs than other nanoparticles.

Keywords: Boron nanoparticle, natural convection, volumetric fraction, square enclosure, nanofluid.

\section{Giriş}

İnsan hayatında kullanımı yaklaşık olarak 4000 yıllık bir geçmișe sahip olan ve saf olarak 1808 yılında elde edilen bor (B) elementi dünya üzerinde sayılı bölgelerde çıkarılmaktadır. Ülkemizin de içinde bulunduğu coğrafya dünyadaki bor rezervlerinin \%73'lük bir kısmını barındırmaktadır. Geri kalan rezervlerin büyük bir kısmı ise Rusya ve ABD ile Güney Amerika ülkelerinde yer almaktadır. Ülkemiz açısından bu anlamda büyük bir öneme sahip olan bor elementi genel olarak tabiatta mineral veya bileșik şeklinde bulunmaktadır. Bor içeren mineral veya bileşikler ise ticari olarak savunma sanayiinde zırh ve kurşungeçirmez yelek malzemesi olarak, bilişim sektöründe süper iletken veya yarı iletken olarak mikro işlemcilerde, enerji sektöründe yakıt pili veya ısı depolayıcısı olarak, optik sektöründe dürbün, kamera ve mercek camlarının üretiminde, kimya sektöründe korozyon önleyici olarak, metalürji sektöründe kaplama malzemesi olarak, inșaat sektöründe mukavemet arttırıcı olarak, tarım sektöründe küf ve mantar önleyici olarak, tıp sektöründe kanser tedavileri başta olmak üzere birçok alanda kullanılmaktadır. Bu alanlardan biri de nanoteknolojidir. Nano boyuttaki parçacıklarla ilgilenen bu teknoloji günümüzde etki alanını hızla arttırmaktadır.

Teknolojik gelișmeyle birlikte özellikle su veya havanın tek fazlı akışkan olarak kullanıldığı ve ısı transferinin doğal taşınımla gerçekleștiği sistemler günlük hayatımızda sıkça kullanılmaktadır. Binalarda ısı yalıtımı uygulamaları, nükleer reaktör tasarımı, yiyecek depolama sistemleri, damitma işlemleri, metallerin ve elektronik cihazların soğutulması bu uygulamalara örnek teşkil eder. Kapalı ortamlarda meydana gelen doğal taşınımla ısı transferi çalıșmaları 1980 yllı ve sonrasında giderek artmıştır. Büyük bir çoğunluğu sayısal olan bu çalıșmalarda, uygulanmasının daha yaygın olması dolayısıyla kare kesitli kapalı ortamlar tercih edilmiştir. Bir düşey duvarından ısıtılan diğer düşey duvarından soğutulan kare ortamda meydana gelen doğal taşınımla ISı transferi de Vahl Davis [1] tarafından incelenmiștir. Laminer doğal taşınım sınırları içerisinde yapılan çalışmada sonlu farklar metodu kullanılmıștır. Duvarlarından farklı şekilde ısıtılan küp şeklindeki üç boyutlu kapalı ortamda gerçekleșen doğal taşınımla ısı transferi Fusegi vd. [2] tarafından araştırılmıştır. Ortam içerisindeki akış ve isı transferine ait karakteristikler belirlenmeye çalışılmıştır. Elde edilen sonuçlarla deneysel sonuçların büyük oranda örtüştüğü görülmüştür. Barakos vd. [3] sonlu kontrol hacmi metodunu kullanarak kare ortamdaki laminer ve türbülanslı doğal taşınımı incelemişlerdir. Deneysel sonuçlarla karşılaştırmaların da yapıldığı çalıșmada farklı şekilde isıtılan duvarlardan olan isı transferini belirleyebilmek için Rayleigh sayısına bağlı ampirik bağıntılar elde edilmiștir. Markatos ve Pericleous [4] kare ortam içerisindeki laminer ve türbülanslı doğal tașınımı Rayleigh sayısının 103-1016 aralığında araştırmışlardır. Rayleigh sayısının $10^{6}$ dan büyük değerlerinde k$\varepsilon$ türbülans modeli kullanılmıștır. Yapılan çalışma sonucunda laminer ve türbülanslı doğal taşınım için ampirik bağıntılar elde edilmiştir. Gelişen teknolojiyle birlikte ana akıșkan ile nanoparçacıkların bir araya gelmesiyle olușan nanoakışkanlarda çoğunlukla ana akışkan olarak su, etilen glikol, yağ, gliserin vb sıvılar kullanılırken nanoparçacık olarak da bakır $(\mathrm{Cu})$, gümüş $(\mathrm{Ag})$, alüminyum (Al), titanyum dioksit $\left(\mathrm{TiO}_{2}\right)$ karbon nanotüp (CNT) kullanılmaktadır. İlk olarak Choi ve Eastman [5] tarafindan ana akışkan içerisine metalik nanoparçacıkların ilave edilmesiyle isı transferinde büyük artışların meydana geldiği görülmüştür. Kullanılan nanoparçacık türü ve șekli, ana akışkanın cinsi, hacimsel karışım oranı, nanoparçacık büyüklüğü gibi parametreler nanoakışkanın termofiziksel özelliklerini büyük oranda değiştirmektedir. $\mathrm{Bu}$ nedenle günümüzde geleneksel akışkan olarak kullanılan su ve diğer akışkanların içine belirli oranlarda nanoparçacık eklenmesiyle termofiziksel özelliklerde iyileștirmeler yapılmaktadır. Daha 
cok isı transferi uygulamalarında kendisine yer bulan nanoakıșkanlar ile ısı transferinde büyük oranda artışlar sağlanmaktadır. Böylece daha küçük bir hacimde istenilen oranda ısı transferi gerçekleștirilebilmektedir. $\mathrm{Bu}$ özelliği dolayısıyla özellikle ısı değiștiricilerinde nanoakışkanların kullanımı gün geçtikçe yaygınlaşmaktadır. Ancak belirli bir hacimsel karışım oranının üzerine çıkıldığında nanoakışkan içerisindeki nanoparçacıklarda çökelme olayı ve beraberinde topaklanma görülmekte, bunun sonucunda da nanoparçacıkların ısı transfer yüzey alanı azaldığı için nanoakıșkanın hem viskozite hem de isıl iletkenlik değerlerinde kötüleșmeler görülmektedir.

Genel olarak literatür incelendiğinde bor elementi ve bileşiklerinin endüstride birçok alanda kullanıldığı görülmektedir. Tombal vd. [6], bor elementinin fiziksel ve kimyasal özelliklerini tablolar halinde düzenleyip bor mineralleri ve bileşiklerinin kullanım alanları ile nükleer reaktörlerde kullanımı hakkında genel bilgiler vermișlerdir. Boron nitrit nanoparçacıklar ilave edilen etilen glikol nanoakışkanında hacimsel karıșım oranına bağlı olarak ısı iletimindeki artış Zyla vd. [7] tarafından deneysel olarak çalıșılmıştır. Yapılan çalıșma sonucunda nanoakıșkanın ısıl iletiminde boron nitritin \%12 hacimsel karıșım oranında ana akıșkana göre \%260'lk bir artıș sağlanmıştır. Wan vd. [8], yağlama yağı içerisine $\% 0.1$ oranında boron nitrit nanoparçacıkları katılmasının tribolojik etkilerini incelemișlerdir. Ortaya çıkan nanoyağlayıcının sürtünme katsayısını \%77'ye varan oranda azalttığ deneysel olarak belirlenmiștir. Küre şekilli, suda çözünebilir boron nitrit nanoparçacıklarının su ile karıșımından olușan nanoakıșkanın isı iletimindeki değişim Han vd. [9] tarafından deneysel olarak çalıșılmıștır. Su bazlı akıșkana göre \% 0.10 hacimsel karıșımda ısıl iletkenliğin \%55 arttığı görülmüș ve nanoakıșkanın kararlılı̆̆ının uzun süre devam ettiği belirlenmiştir. Salles vd. [10], boron nitrit nanoparçacıklarının yapısal ve ısıl özelliklerini deneysel olarak incelemişlerdir. Boron nitrit nanoparçacıkların ana akışkan olan suya \% 6 oranında katılmasıyla ısıl iletkenlikte 2.6 kat artış sağlandığı Zhi vd. [11] tarafından deneysel olarak belirlenmiștir. Nanoparçacıkların büyüklüğü ve șekli ile kimyasal fonksiyonlarının biyolojik sistemlere etkileri Albanese vd. [12] tarafından araștırılmıștır. Teknolojinin gelișmesiyle birlikte biyolojik sistemlerde kullanılan nanoparçacıklar hakkında geniș bir araştırma sunulmuştur. Kong vd. [13], nanoakışkanların hazırlanması, karakterizasyonu ve tribolojik mekanizmaları hakkında geniş bilgiler veren bir derleme çalışması yapmışlardır. Sırasıyla nanoakışkanların sentezi, kararlılığının arttırılması, karakterizasyonu ve yağlama mekanizmaları hakkında detaylı bilgiler verilmiştir. Yağ bazlı nanoakışkanların hazırlanma metotları ve termofiziksel özellikleri Asadi vd. [14] tarafından derlenmiştir. Derleme çalışmasında hem soğutma, hem de yağlama işlemlerinde kullanılan nanoparçacıkların konsantrasyonu, şekli ve sıcaklığı gibi parametrelerin nanokıșkanın isıl iletkenlik, viskozite, yoğunluk ve özgül ısı gibi termofiziksel özelliklerine etkileri verilmiştir. Buongiorno [15] nanoakışkanlardaki taşınım olaylarını incelemiş ve ısınan akışkanın sınır tabaka içerisinde viskozitesi azalırken ısı transferinin arttığını belirlemiștir. Ana akışkan olarak kullanılan suyun içerisine farklı hacimsel karışım oranlarında bakır nanoparçacıkların katılmasının ısı transferine etkisini Khanafer vd. [16] sayısal olarak çalışmışlardır. Yapılan sayısal çalışmada Grashoff sayısının $10^{3} \leq \mathrm{Gr} \leq 10^{5}$ ve hacimsel karışım oranının \%0-20 aralığındaki değișiminin doğal tașınımla isı transferine etkileri incelenmiştir. Nanoparçacık ilavesinin Isı transferini arttırdığı belirlenmiștir. Öğ̈̈ [17] içerisi su bazlı nanoakışkanla dolu eğimli kare kapalı ortam için sol düşey duvarının merkezine yerleștirilmiş bir ısı kaynağının farklı boylara sahip olması durumundaki doğal taşınımla isı transferini sayısal olarak incelemiştir. Isıtıcı boyunun artmasıyla birlikte isı transferinin de arttığı görülmüştür. Ayrıca nanoparçacık oranının artıșıyla birlikte ısı transferinde lineere yakın bir artış olduğu kaydedilmiştir. Eğik kapalı ortamın sol duvarının yüksek sıcaklıkta, üst duvarının düşük sıcaklıkta olması durumundaki doğal taşınımla ısı transferi Öğ̈̈t [18] tarafından incelenmiștir. Bakır, gümüș ve alüminyum oksit nanoparçacıklarının kullanıldığı çalışmada nanoparçacık karıșım oranının ve Rayleigh sayısının artışının ısı transferini arttırdığı belirlenmiştir. Ayrıca eğim açısının $60^{\circ}$ olması durumunda isı transferinin minimum olduğu tespit edilmiștir. Ben-Cheikh vd. [19] alt duvar sıcaklığı sinüzoidal olarak değișen diğer duvarları düșük sıcaklıktaki kare kapalı ortamın su bazlı farklı hacimsel karıșım oranlarına sahip 
nanoparçacıklar ile dolu olması durumundaki doğal taşınımla ısı transferini sayısal olarak incelemişlerdir. Rayleigh sayısının $5 \times 10^{3} \leq \mathrm{Ra} \leq 5 \times 10^{5}$ ve hacimsel karıșım oranının \%0-20 aralığındaki parametreler incelendiğinde düşük Rayleigh sayılarında ve yüksek hacimsel karıșım oranlarında ısı transferinin \% 55 oranında arttığı belirlenmiştir. Görüldüğü gibi nanoakışkanlar ile ilgili çalışmalarda genel olarak Rayleigh sayısı, hacimsel karıșım oranı, nanoparçacık ve ana akışkan cinsi gibi parametreler incelenmektedir. Bunların dıșında kapalı ortam geometrisinin de isı transferini önemli oranda değiștirdiği bilinen bir gerçektir. Ho vd. [20] bir düșey duvarından isıtılan diğerinden soğutulan kare ortamın $\mathrm{Al}_{2} \mathrm{O}_{3}$-su nanoakıșkanı ile dolu olması durumunu araştırmışlardır. Aynı sınır koşulları altında $\mathrm{Al}_{2} \mathrm{O}_{3}$-su nanoakışkanı ile dolu kare ortamda manyetik alan etkisi altında gerçekleşen doğal taşınımla isı transferi Ghasemi vd. [21] tarafından incelenmiştir. Aynı sınır koşulları ve nanoakışkan için deneysel çalışma Ho vd. [22] tarafından yapılmıștır. Abu-Nada ve Oztop [23] bakır-su nanoakıșkanı ile dolu kare ortamın farklı eğim açılarındaki ısı transferi değişimlerini incelemişlerdir. Alt duvarından bir ısı kaynağıyla ısıtılan, diğer duvarlarından soğutulan nanoakışkan ile dolu kare ortamdaki doğal tașınımla ısı transferi Aminossadati ve Ghasemi [24] tarafından çalışılmıştır. İncelenen nanoparçacıklar ise $\mathrm{Cu}, \mathrm{Ag}, \mathrm{Al}_{2} \mathrm{O}_{3}$ ve $\mathrm{TiO}_{2}$ ' dir. Katı nanoparçacık hacimsel karışım oranının artmasıyla ısı kaynağının maksimum sıcaklığının kısmen azaldığı ve düşük Rayleigh sayılarında iletimin başlıca ısı transfer mekanizması olduğu bulunmuştur. Sol düşey duvarından kısmen ısıtılan sağ düșey duvarından soğutulan farklı en/boy oranlarına sahip kapalı ortamın $\mathrm{Cu}, \mathrm{Al}_{2} \mathrm{O}_{3}$ ve $\mathrm{TiO}_{2}$ nanoparçacıklarından olușan nanoakışkan ile dolu olması durumunda gerçekleşen ısı transferi Oztop ve Abu-Nada [25] tarafından incelenmiştir. Bakır-su nanoakışkanı ile dolu farklı en/boy oranına sahip dikdörtgen kapalı ortamdaki doğal tașınımla ısı transferi Jou ve Tzeng [26] tarafindan araştırılmıștır. Alloui vd. [27] içerisi $\mathrm{Cu}, \mathrm{Ag}, \mathrm{Al}_{2} \mathrm{O}_{3}, \mathrm{CuO}$ ve $\mathrm{TiO}_{2}$ nanoparçacıklar ihtiva eden nanoakışkan ile dolu düşey duvarları yalıtılan sığ bir kapalı ortamın yatay duvarlarına Neumann sınır koşullarının uygulanması durumunu detaylıca araștırmıșlardır. Abu-Nada vd. [28] farklı en/boy oranlarına sahip dikdörtgen kapalı ortamın $\mathrm{Al}_{2} \mathrm{O}_{3}$-su veya $\mathrm{CuO}$-su nanoakışkanı ile dolu olması durumunda nanoakıșkan özelliklerinin belirlenmesinde farklı modellerin etkisini incelemişlerdir. Bouhalleb ve Abbassi [29] CuOsu nanoakışkanı ile dolu dikdörtgen ortamın farklı eğim açıları altında sol duvar sıcaklığının sinüzoidal olarak değişimini araştırmışlardır. Alloui vd. [30] $\mathrm{Cu}, \mathrm{Al}_{2} \mathrm{O}_{3}$ ve $\mathrm{TiO}_{2}$ nnoparçacıkları içeren nanoakışkan ile dolu sığ bir kapalı ortamın düșey duvarlarına Neumann sınır koşullarını uygulamışlardır.

Mahmoudi vd. [31] dik üçgen kesitli kapalı ortamın alt duvarından kismi olarak isitılıp eğimli olan duvarından soğutulması durumunu bakır-su nanoakıșkanı için farklı manyetik alan etkisi altında incelemişlerdir. Sol duvarından kısmen ısıtılan eğimli duvarından soğutulan dik üçgen kesitli ortamın CuO-su nanoakıșkanı ile dolu olması durumundaki Brownian hareketi etkisini Ghasemi ve Aminossadati [32] incelemiștir. Aminossadati ve Ghasemi [33] bir diğer çalışmalarında eğimli duvarlarından soğutulan alt duvarından kısmen ısıtılan ikizkenar üçgenin etilen glikol-bakır nanoakıșkanı içermesi durumunda ısı transferini artırmak için farklı parametreleri incelemişlerdir. Selimefendigil ve Öztop [34] içerisinde dönen bir disk bulunan sol duvarından ısıtılan dik üçgen kesitli ortamdaki MHD doğal taşınımı bakır-su nanoakışkanı için incelemişlerdir. Sun ve Pop [35] sol düșey duvarından kısmen ısıtılan, eğimli duvarından soğutulan dik üçgen kesitli gözenekli ortamın farklı nanoakışkanlar içermesi durumunda gerçekleșen Isı transferini incelemișlerdir.

Saleh vd. [36] eğimli bir duvarından isıtılan diğerinden soğutulan yamuk şeklindeki kapalı ortamın $\mathrm{Cu}$-su ve $\mathrm{Al}_{2} \mathrm{O}_{3}$-su nanoakıșkanı ile dolu olması durumunda isı transferinde meydana gelen değișimleri incelemișlerdir. Mahmoudi vd. [37] alt duvarından kısmen isıtılan yamuk şeklindeki kapalı ortamda gerçekleşen MHD doğal taşınımı ve entropi üretimini $\mathrm{Cu}$-su nanoakıșkanı kullanılması durumunda incelemișlerdir. Esfe vd. [38] yamuk șeklindeki kapalı ortamın CNT-EG-su nanoakıșkanı ile dolu olması durumundaki doğal taşınımı düşey duvarların farklı eğim açıları için araştırmışlardır. Bondareva vd. [39] yamuk kesitli kapalı ortama uygulanan manyetik alanın ISı transferine etkisini birçok parametre için araştırmışlardır. Nasrin ve Parvin [40] sol duvarından isıtılan sağ duvarından soğutulan yamuk kesitli kapalı ortamın $\mathrm{Cu}$-su nanoakışkanı ile dolu olması durumundaki akış ve ısı transferi 
değișimlerini incelemișlerdir. Miroshnichenko vd. [41] CuO-su nanoakışkanı ile dolu yamuk kesitli kısmen açık kapalı ortamdaki MHD doğal taşınımı araştırmışlardır.

Soleimani vd. [42] iç yüzeyinden ısıtılan diş yüzeyinden soğutulan yarı halka kesitli kapalı ortamın $\mathrm{Cu}$-su nanoakışkanı ile dolu olması durumu için doğal taşınımla ısı transferini incelemişlerdir. Sheikholeslami vd. [43] eliptik silindirin CuO-su nanoakışkanı ile dolu olması durumundaki doğal taşınımla ısı transferini araștırmıșlardır. Al-Zamily [44] yarım daire kesitli ortamın alt duvarından kısmen ısıtılması durumunda uygulanan manyetik alanın doğal taşınımla isı transferine etkisini $\mathrm{Cu}$-su nanoakışkanı için incelemiştir. Ali vd. [45] su bazlı $\mathrm{Al}_{2} \mathrm{O}_{3}$ nanoakışkanla dolu dikey dairesel kapalı ortam içindeki doğal taşınımla ısı transferini deneysel olarak çalışmışlardır.

Daha önceden yapılan çalıșmalar incelendiğinde birçok nanoparçacık türünün isı transferi üzerindeki etkilerinin araştırıldığı görülmüștür. Yapılan çalışmada bor nanoparçacıklarının ana akışkan olarak suyun kullanıldığı nanoakışkandaki farklı hacimsel karışım oranlarında ısı transferi ve akışkan akımına olan etkisi incelenmiştir. Uygulamada genel olarak kullanılan nanoparçacıklar olan bakır $(\mathrm{Cu})$ ve alüminyum oksit $\left(\mathrm{Al}_{2} \mathrm{O}_{3}\right)$ ile bor nanoparçacıkları için farklı karışım oranlarındaki ısı transferi ve akışkan akımı değişimleri karşılaştırmalı olarak incelenmiştir. Böylece bor nanoparçacık kulanımının etkinliği belirlenmeye çalışılmıștır.

\section{Materyal ve Metot}

Kare kesitli kapalı ortama ait geometri Şekil 1' de verilmiștir. İncelenen geometri için kapalı ortamın uzunluğu ve yüksekliği birbirine eşittir $(\mathrm{L}=\mathrm{H})$. Kare kesitli ortam sol duvarından isıtılmakta $\left(\mathrm{T}_{\mathrm{h}}\right)$, sağ duvarından ise soğutulmaktadır $\left(\mathrm{T}_{\mathrm{c}}\right)$. Kapalı ortamın üst ve alt duvarları ise yalıtılmıştır.

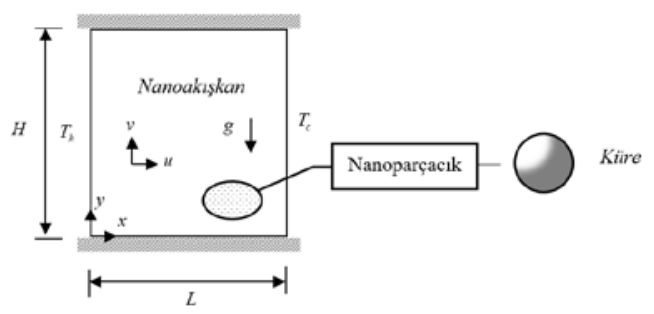

Şekil 1. Kapalı ortam geometrisi ve nanoparçacıkların şekli.
Ana akıșkan olarak suyun kullanıldığ sistemde akışkana nanoparçacıklar ilave edilerek oluşturulan nanoakışkan, kapalı ortamı tamamen doldurmaktadır. Kullanılan nanoakışkan Newtoniyen özellikli olup kapalı ortamın her yerinde homojen özellikler göstermektedir ve sıkıştırılamaz kabul edilmiştir. Nanoakışkanın bileşenlerine ait termofiziksel özellikler Tablo 1'de verilmiştir.

Tablo 1. Nanoakışkanın bileșenlerine ait termofiziksel özellikler.

\begin{tabular}{|l|c|c|c|c|}
\hline & \multicolumn{4}{|c|}{ Termofiziksel özellik } \\
\cline { 2 - 5 } & $\begin{array}{c}\mathrm{c}_{\mathrm{p}} \\
(\mathrm{J} / \mathrm{kgK})\end{array}$ & $\begin{array}{c}\rho \\
\left(\mathrm{kg} / \mathrm{m}^{3}\right)\end{array}$ & $\begin{array}{c}\mathrm{k} \\
(\mathrm{W} / \mathrm{mK})\end{array}$ & $\begin{array}{c}\beta \times 10^{-5} \\
(1 / \mathrm{K})\end{array}$ \\
\hline $\begin{array}{l}\text { Ana } \\
\text { akışkan } \\
(\mathrm{H} 2 \mathrm{O})\end{array}$ & 4179 & 997.1 & 0.613 & 21 \\
\hline $\mathrm{B}$ & 1020 & 2340 & 27.4 & 83 \\
\hline $\mathrm{Cu}$ & 385 & 8933 & 401 & 1.67 \\
\hline $\mathrm{Al}_{2} \mathrm{O}_{3}$ & 765 & 3970 & 40 & 0.85 \\
\hline
\end{tabular}

Ana akıșkan ve nanoparçacıklar isıl olarak dengede olup nanoakışkana ait yoğunluk dışındaki bütün özellikler sıcaklıktan bağımsızdır ve Boussinesq yaklașımı geçerlidir. Kapalı ortam içerisindeki akış iki boyutlu ve zamandan bağımsız olup laminer kabul edilmiștir. İki boyutlu problem geometrisinin çözümü için geliştirilen korunum denklemleri boyutsuz şekilde verilirse;

$\frac{\partial U}{\partial X}+\frac{\partial V}{\partial Y}=0$

$U \frac{\partial U}{\partial X}+V \frac{\partial U}{\partial Y}=-\frac{\partial P}{\partial X}$ $+\frac{\mu_{n f}}{\alpha_{n f} \alpha_{f}}\left(\frac{\partial^{2} U}{\partial X^{2}}+\frac{\partial^{2} U}{\partial Y^{2}}\right)$

$U \frac{\partial V}{\partial X}+V \frac{\partial V}{\partial Y}=-\frac{\partial P}{\partial Y}$

$$
\begin{aligned}
& +\frac{\mu_{n f}}{\alpha_{n f} \alpha_{f}}\left(\frac{\partial^{2} V}{\partial X^{2}}+\frac{\partial^{2} V}{\partial Y^{2}}\right) \\
& +\frac{(\rho \beta)_{n f}}{\rho_{n f} \beta_{f}} \operatorname{RaPr} \theta
\end{aligned}
$$$$
U \frac{\partial \theta}{\partial X}+V \frac{\partial \theta}{\partial Y}=\frac{\alpha_{n f}}{\alpha_{f}}\left(\frac{\partial^{2} \theta}{\partial X^{2}}+\frac{\partial^{2} \theta}{\partial Y^{2}}\right)
$$ 
elde edilir. Denklemlerde kullanılan boyutsuzlaștırma parametreleri

$X=\frac{x}{L}, \quad Y=\frac{y}{L}, \quad U=\frac{u L}{\alpha_{f}}, V=\frac{v L}{\alpha_{f}}$,

$P=\frac{p L^{2}}{\rho_{n f} \alpha_{f}^{2}}, \theta=\frac{T-T_{c}}{T_{h-} T_{c}}$

şeklindedir. Denklemlerde verilen $U$ ve $V$ sırasıyla yatay ve düșey doğrultudaki boyutsuz hız bileşenleridir. Boyutsuz sıcaklık $\theta$ ile boyutsuz basınç ise $P$ ile temsil edilmektedir. $Y$ yönündeki momentum denkleminde ortaya çıkan boyutsuz sayılar Rayleigh sayısı $(R a)$ ve Prandtl sayısı $(\mathrm{Pr})$ olup

$R a=\frac{g \beta_{f} L^{3}\left(T_{h-} T_{c}\right)}{v_{f} \alpha_{f}}, \operatorname{Pr}=\frac{v_{f}}{\alpha_{f}}$

şeklinde elde edilir. Nanoparçacıkların ana akışkan içerisindeki hacimsel karışım oranı $\phi$ olmak üzere nanoakıșkana ait termofiziksel özellikler hesaplanırsa;

$\rho_{n f}=(1-\phi) \rho_{f}+\phi \rho_{p}$

$\left(\rho c_{p}\right)_{n f}=(1-\phi)\left(\rho c_{p}\right)_{f}+\phi\left(\rho c_{p}\right)_{p}$

$(\rho \beta)_{n f}=(1-\phi)(\rho \beta)_{f}+\phi(\rho \beta)_{p}$

$\alpha_{n f}=\frac{k_{n f}}{\left(\rho c_{p}\right)_{n f}}$

elde edilir. Küresel şekilli nanoparçacıklar için nanoakışkanın ısı iletim katsayısı Maxwell [46] tarafindan verilen

$k_{n f}=k_{f}\left(\frac{k_{p}+2 k_{f}-2 \phi\left(k_{f}-k_{p}\right)}{k_{p}+2 k_{f}+\phi\left(k_{f}-k_{p}\right)}\right)$

denklemi ile elde edilmiştir. Düşük hacimsel karışım oranları için nanoakışkanın dinamik viskozitesi Brinkman [47] modeline göre

$\mu_{n f}=\frac{\mu_{f}}{(1-\phi)^{2.5}}$

şeklinde elde edilir. Akışkan akımını göstermek için kullanılan akım fonksiyonu

$u=\frac{\partial \psi}{\partial y}, \quad v=-\frac{\partial \psi}{\partial x}$ denklemleri yardımıyla bulunur. İncelenen iki boyutlu kare kesitli kapalı ortam için bütün duvarlarda kaymama sınır koşulu $(\mathrm{U}=\mathrm{V}=0)$ geçerli olup her bir duvara ait ısıl sınır koşullar boyutsuz olarak aşağıda verilmiştir:

Sol duvarda, $\mathrm{X}=0$ ' da $\theta=1$

Sağ duvarda, $X=L$ 'de, $\theta=0$

Alt duvarda, $\mathrm{Y}=0^{\prime} \mathrm{da}, \quad \frac{\partial \theta}{\partial Y}=0$

Üst duvarda, $\mathrm{Y}=\mathrm{H}^{\prime} \mathrm{de}, \frac{\partial \theta}{\partial Y}=0$

Farklı parametrelerin taşınımla ısı transferine etkisini belirlemek amaciyla Nusselt sayısından faydalanılır. Nusselt sayısının yerel ve ortalama değerleri sol düşey duvar için hesaplanacak olursa;

$N u_{h}=-\left.\left(\frac{k_{n f}}{k_{f}}\right) \frac{\partial \theta}{\partial X}\right|_{X=0}$

$\overline{N u_{h}}=\frac{1}{H} \int_{0}^{H} N u_{h} d Y$

elde edilir. Problemin çözümü için geliștirilen korunum denklemleri Patankar [48] tarafindan verilen SIMPLE (Semi Implicit Pressure Linked Equations) algoritmasına göre sonlu kontrol hacmi metodu (FVM) yardımıyla iteratif olarak çözülmüştür. Ayrıklaştırılan denklemleri çözmek için bir FORTRAN programı geliștirilmiștir. Ana akıșkan olarak kullanılan su için Prandtl sayısı 6.2 olarak alınmıştır. Problemin çözümünde uygun ağ sıklığını bulmak

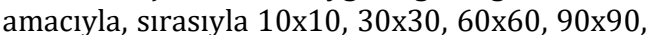
$120 \times 120$ ve $150 \times 150$ eș dağılı ağ sıklıkları için Rayleigh sayısının $10^{5}$ değerindeki ortalama Nusselt sayılarının değişimi Şekil 2'de verilmiștir. Şekilden de görüldüğü gibi 90x90 ağ sıklığından sonra \%1'den daha küçük değișimler meydana gelmektedir. Bu nedenle elde edilen çözümlerin daha kısa zaman alması amacıyla bütün çözümlerde $90 \times 90$ ağ sıklığı kullanılmış olup çözüme ait yakınsama kriteri ise

$\left|\frac{\varphi_{i, j}^{m+1}-\varphi_{i, j}^{m}}{\varphi_{i, j}^{m}}\right| \leq 10^{-7}$

şeklinde verilmiştir. Çözüm iteratif olarak elde edildiği için Eș. 15'te verilen m iterasyon sayısını, $\varphi$ ise genel bir bağımlı değişkeni $(U, V, \theta)$ belirtmektedir. 


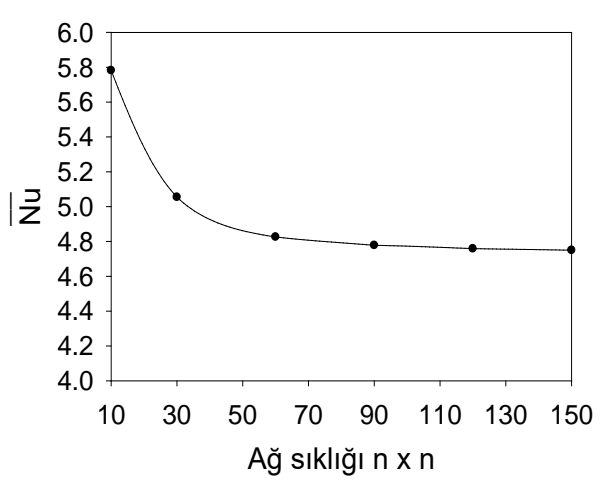

Şekil 2. Ra=105 için ağ sıklığına bağlı olarak ortalama Nusselt sayısının değişimi

Yapılan çalışmanın doğruluğunu göstermek için aynı sınır koşullarında içerisi hava ile dolu kare kesitli kapalı ortam için literatürdeki çalışmalarla karşılaştırma yapılmıştır. Şekil 3'te farklı Rayleigh sayılarında elde edilen sonuçların büyük oranda benzer olduğu görülmektedir. Elde edilen sonuçlar ile literatürdekiler arasındaki fark \% 2'nin altındadır.

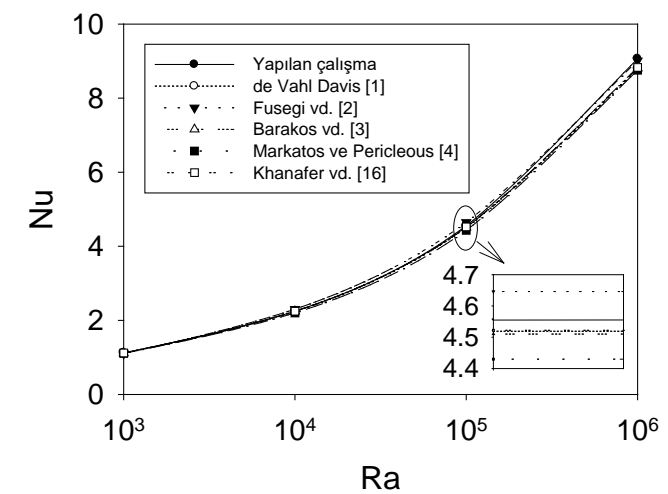

Şekil 3. Farklı Rayleigh sayılarında ortalama Nusselt sayılarının literatürle karşılaştırılması.

\section{Bulgular}

Sol düşey duvarından ısıtılan sağ düşey duvarından soğutulan yatay duvarları yalıtılmış kare kesitli kapalı ortamın ana akışkan olarak suyun kullanıldığı küresel şekilli bor nanoparçacıklar ilave edilmiș nanoakıșkan ile dolu olması halinde meydana gelen doğal taşınımla ISı transferi sayısal olarak incelenmiştir. Bor nanoparçacıkların sırasıyla $\% 0,2$ ve 4 hacimsel karışım oranlarında, Rayleigh sayısının $10^{4}-10^{6}$ aralığı için laminer doğal taşınım koşullarında çalışma yapılmıştır. Farklı Rayleigh sayıları ve hacimsel karıșım oranları için bor-su (B- $\left.\mathrm{H}_{2} \mathrm{O}\right)$ nanoakıșkanında meydana gelen akış olayları ve sıcaklık dağılımları Şekil 4'te akım çizgileri ve eş sıcaklık eğrileri şeklinde verilmiștir. Rayleigh sayısının düşük değerlerinde akım çizgileri kapalı ortamın merkezi etrafında yoğunlașmakta olup saat yönünde bir akıș meydana gelmektedir. Rayleigh sayısının artmasıyla birlikte aynı yönlü iki akım hücresi yine kapalı ortamın merkezi civarında yatay olarak genişleyerek saat yönünde akmaktadır. Ayrıca sabit bir Rayleigh sayısındaki akım çizgileri incelendiğinde hacimsel karışım oranının artmasıyla birlikte akım şiddetinin de arttığı görülmektedir. $\mathrm{Bu}$ davranış Rayleigh sayısının diğer değerlerinde de görülmektedir. Eş sıcaklık eğrileri incelendiğinde düşük Rayleigh sayılarında kaldırma kuvveti etkisi daha az olduğu için kapalı ortamın sol üst ve sağ alt bölgelerine yakın yerlerde akışın da etkisiyle birlikte eş sıcaklık eğrilerinin iç ortama doğru kaydığı görülmektedir. Benzer durum Rayleigh sayısının artışıyla birlikte daha iç bölgelere kadar ilerlemektedir. Ayrıca yüksek Rayleigh sayılarında kapalı ortamın sıcak olan sol duvarı ile soğuk olan sağ duvarı civarında eş sıcaklık eğrilerinin sıklaştığı tespit edilmiştir. 
DEÜ FMD 22(66), 701-714, 2020

$\mathrm{Ra} \phi$

$\psi$

$\theta$

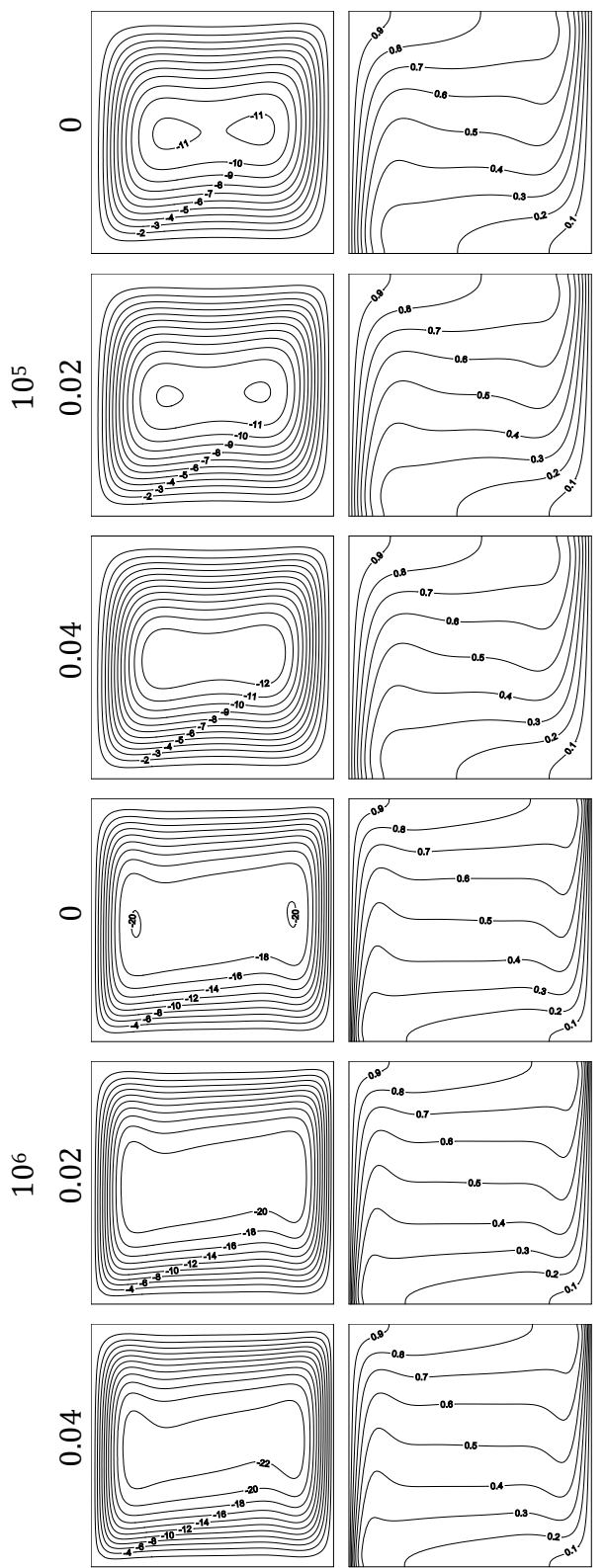

Şekil 4. Bor nanoparçacıklarının farklı hacimsel karışım oranlarındaki akım çizgileri (solda) ve eşsıcaklık eğrileri (sağda) (Ra=105 ve $\left.10^{6}\right)$.

Rayleigh sayısının $10^{5}$ değerindeki akım çizgilerinin ve eşsıcaklık eğrilerinin hacimsel karışım oranıyla değişimi aynı geometri üzerinde Sekil 5'te verilmiștir. Sekilden de görüldüğü gibi hacimsel karışım oranının artışıla akım fonksiyonu değerleri artarak kapalı ortamın merkezine doğru yaklașmaktadır. Eşsıcaklık eğrilerinde ise hacimsel karışım oranının çok önemli bir etkisinin olmadığı görülmektedir.

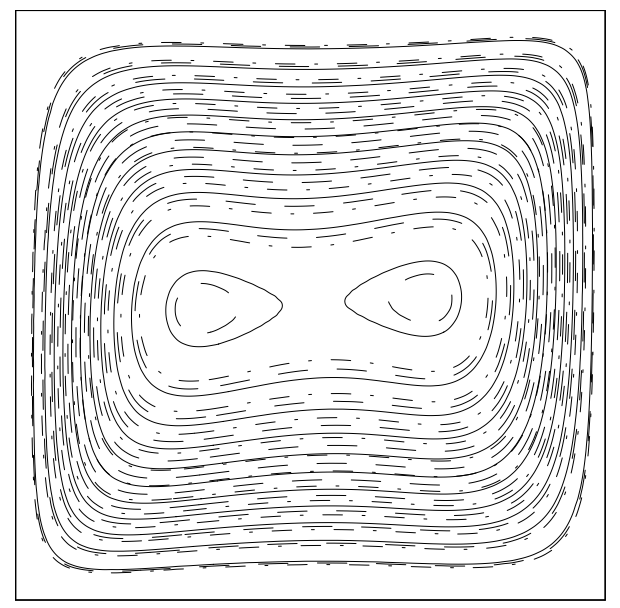

a)

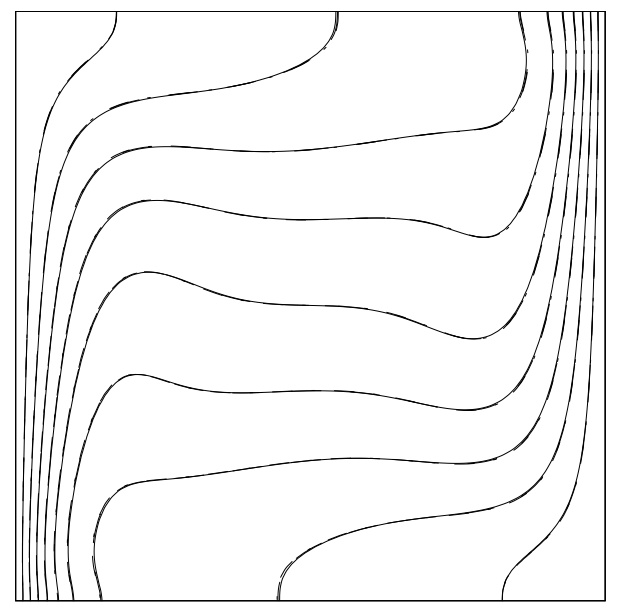

b)

Şekil 5. Bor nanoparçacık kullanımında $\mathrm{Ra}=10^{5}$ için farklı hacimsel karışım oranlarındaki ($\phi=\% 0,--\phi=\% 2,-\cdot-\phi=\% 4$ ) a)akım çizgileri ve b)eşsıcaklık eğrileri. 

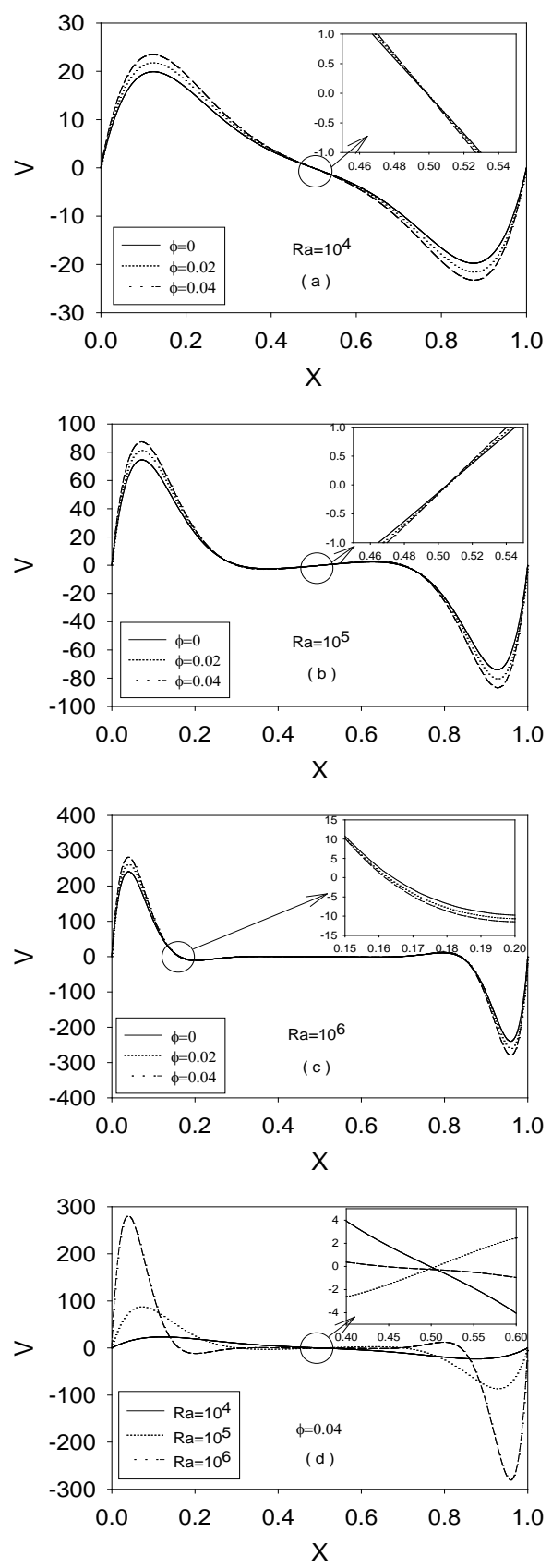

Şekil 6. Farklı Rayleigh sayıları ve hacimsel karışım oranları için bor nanoparçacık kullanımında kapalı ortamın orta kesiti boyunca $(\mathrm{Y}=0.5)$ değişen düşey hız profilleri

Kapalı ortamın orta kesitindeki düșey hız profillerinin Rayleigh sayısı ve hacimsel karıșım oranlarına bağlı olarak değișimleri Șekil 6'da verilmiştir. Düşey hız profilleri incelendiğinde bütün Rayleigh sayılarında en yüksek yerel hız değerlerinin hacimsel karıșım oranının \% 4 olması durumunda gerçekleştiği, daha sonra $\% 2$ hacimsel karıșım oranında görüldüğü belirlenmiştir. En düşük yerel hız değerleri ise ana akışkan olarak suyun kullanıldığı durumda gerçekleşmiştir. Sabit bir hacimsel karıșım oranında Rayleigh sayısının artmasıyla birlikte düşey hız değerlerinin genliğinin de arttığı Șekil 6 d'de açıkça görülmektedir. Kapalı ortamın sıcak olan sol düșey duvarına yakın bölgede kaldırma kuvveti etkisiyle yukarı doğru olan düșey hız profilleri, soğuk olan sağ düșey duvara yakın bölgede ise aşağı yönlü olacak şekilde meydana gelmiștir. Rayleigh sayısının $10^{6}$ değerinde ise belirtilen kesit boyunca meydana gelen hız değișimlerinden, yatay eksen boyunca $\mathrm{X}=0.2$ ile 0.8 değerleri arasında hız değerlerinin sıfıra yaklaştığı Şekil $6 c^{\prime}$ de görülmektedir. Bu aralık değeri Rayleigh sayısının azalmasıyla birlikte Şekil 6a ve Şekil 6b'de olduğu gibi azalmaktadır.

Sabit bir hacimsel karıșım oranı için farklı Rayleigh sayılarında kapalı ortamın orta ekseni boyunca sicaklık profillerinin verildiği Şekil 7'den görüldüğü gibi Rayleigh sayısının artışı ile birlikte sıcaklık profilleri sol ve sağ duvara doğru kaymakta ve kaldırma kuvveti etkisiyle hızlı bir şekilde düşmektedir.

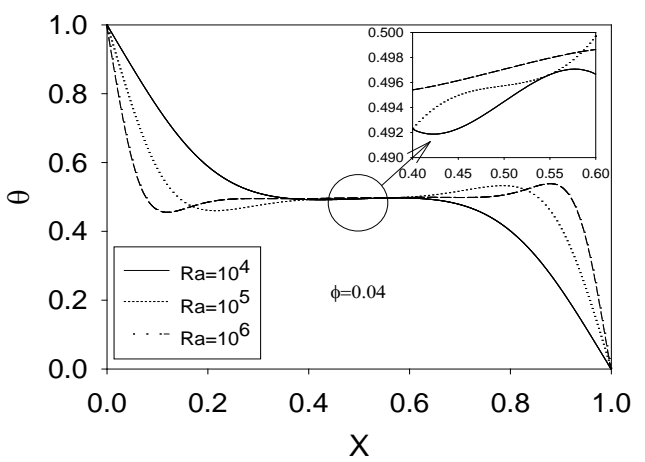

Şekil 7. Farklı Rayleigh sayıları için bor nanoparçacık kullanımında kapalı ortamın orta kesiti boyunca ( $\mathrm{Y}=0.5$ ) değișen sıcaklık profilleri

Yerel Nusselt saylarının sol duvar boyunca hacimsel karıșım oranına ve Rayleigh sayısına bağlı değișimi Șekil 8'de verilmektedir. Sabit bir Rayleigh sayısı için hacimsel karışım oranının artışı Şekil 8a'da görüldüğü gibi ısı transferini arttırmaktadır. Sol duvarın alt kesimine yakın 
bölgelerde düșük sıcaklıklar dolayısıyla ısı transferinin önce arttığı, daha sonra ise isınan akışkan dolayısıyla üst bölgelere doğru azaldığı görülmektedir. Sabit bir hacimsel karışım oranı için Rayleigh sayısının artışıla birlikte artan kaldırma kuvvetleri nedeniyle isı transferinin de yerel olarak arttığı Şekil 8b’den görülmektedir.
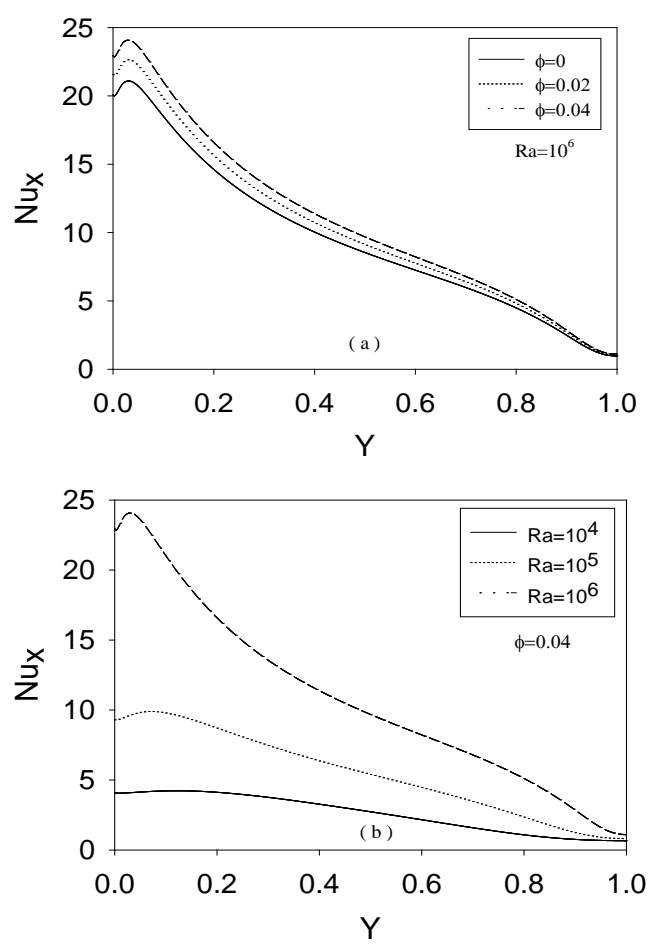

Şekil 8. Farklı hacimsel karıșım oranları (a) ve Rayleigh sayıları (b) için bor nanoparçacık kullanımında sol duvara ait yerel Nusselt sayıları

Bor nanoparçacıklarının ana akışkan olan su ile farklı hacimsel karıșım oranlarındaki ortalama Nusselt sayılarının değişimleri Rayleigh sayısına bağlı olarak Şekil 9'da verilmiştir. Şekilden de görüldüğü gibi Rayleigh sayısının artışının etkisi hacimsel karıșım oranına göre daha fazladır. Rayleigh sayısının $10^{4}$ değeri ile karşılaştırıldığında Rayleigh sayısının $10^{6}$ değerinde isı transferinde \% 316'lara varan oranlarda artış görülmektedir. Rayleigh sayısının bütün değerlerinde hacimsel artış oranının etkisine bakılacak olursa, ana akışkan olan su ile karşılaştırıldığında ısı transferinde \% 14'lere varan bir artış meydana gelmektedir.

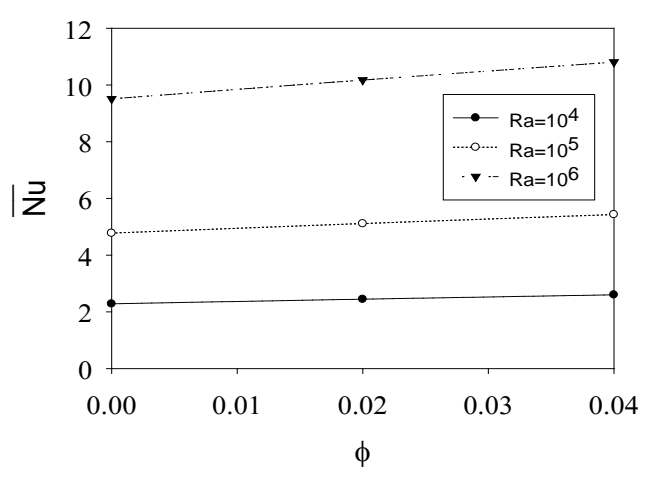

Şekil 9. Bor nanoparçacık kullanılan nanoakışkan için farklı hacimsel karıșım oranlarındaki ortalama Nusselt sayıları

Nanoparçacık olarak bor (B), bakır (Cu) ve alüminyum oksit $\left(\mathrm{Al}_{2} \mathrm{O}_{3}\right)$ ana akıșkan olarak suyun kullanıldığı bir nanoakışkandaki doğal taşınımla gerçekleşen ısı transferinin göstergesi olan ortalama Nusselt sayılarının değişimi farklı Rayleigh sayılarında ve hacimsel karışım oranlarında Sekil 10'da verilmiștir. Ortalama Nusselt sayılarından görüldüğü gibi bütün Rayleigh sayılarında ve hacimsel karıșım oranlarında en yüksek ısı transferi bor nanoparçacık kullanılan nanoakışkanda gerçekleșmiștir. Bor nanoparçacıktan sonra en iyi ısı transferi değerleri bakır (Cu) nanoparçacık kullanılan nanoakışkanda, en düşük ısı transferi değerleri ise alüminyum oksit $\left(\mathrm{Al}_{2} \mathrm{O}_{3}\right)$ nanoparçacık kullanılan nanoakışkanda gerçekleşmiştir.

Ana akışkan olarak suyun kullanıldığı duruma göre bor nanoparçacık kullanılan nanoakışkanda ISI transferinde \%14'e varan bir iyileşme görülmüştür. Bakır nanoparçacıkta bu artış \%5, alüminyum oksit nanoparçacıkta ise \% 4 civarındadır. İncelenen nanoparçacıklar içerisinde bor (B) en düșük ısı iletim katsayısına sahip olmasına rağmen özgül ısısının yüksek ve yoğunluğunun düşük olması nedeniyle doğal taşınımla ısı transferinde kaldırma kuvvetlerinin etkisine bağlı olarak en yüksek ısı transferi değerlerini vermiștir. İncelenen bütün nanoparçacıklar için Rayleigh sayısının artmasıyla birlikte ısı transferi de artmaktadır. Aynı zamanda hacimsel karışım oranının artışı da ısı transferini arttırmaktadır. 

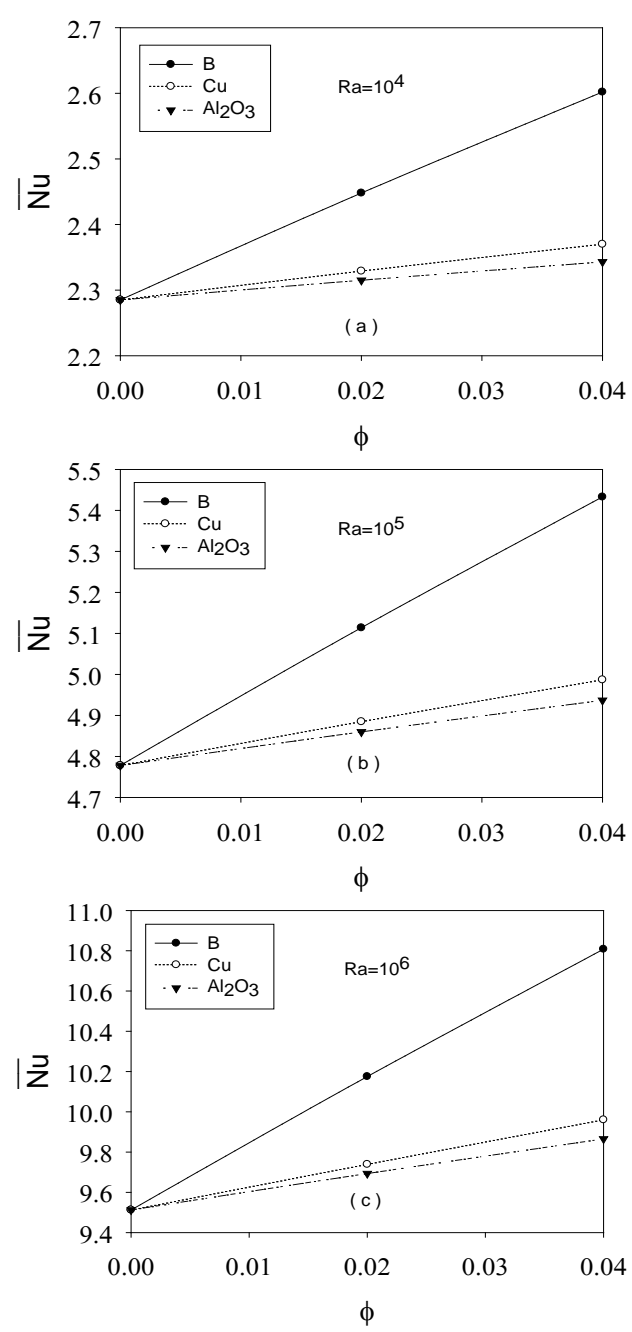

Şekil 10. Farklı hacimsel karışım oranlarındaki ortalama Nusselt sayılarl. a)Ra=104, b) Ra $=10^{5}$, c) $\mathrm{Ra}=10^{6}$.

Ayrıca kullanılan nanoparçacıkların birim fiyatları karşılaştırıldığında bor nanoparçacıkların $\mathrm{Al}_{2} \mathrm{O}_{3}$ nanparçacıklardan yaklaşılk \%300, Cu nanoparçacıklardan \%33 daha pahalı olduğu görülmüştür.

\section{Tartışma ve Sonuç}

Geleneksel doğal taşınım problemini içeren sol duvarından isitılan, sağ duvarından soğutulan yatay duvarları mükemmel bir şekilde yalıtılmış olan kare kesitli kapalı bir ortamın ana akışkan olarak suyun kullanıldığ nanoparçacıkları ilave edilmiş nanoakışkanla dolu olması durumunda gerçekleşen doğal taşınımla ısı transferi problemi sayısal olarak çalışılmıştır. Laminer doğal taşınımın geçerli olduğu Rayleigh sayısının $10^{4}, 10^{5}$ ve $10^{6}$ değerlerinde, nanoparçacık ile suyun hacimsel karışım oranlarının \% 0,2 ve 4 olması durumunda isı transferine etkileri incelenmiștir. Yapılan çalışma sonucunda aşağıdaki bulgular elde edilmiştir:

1. Nanoparçacıkların ana akışkan ile hacimsel karıșım oranının ve aynı zamanda Rayleigh sayısının kapalı ortam içerisindeki doğal tașınımla ısı transferi üzerinde önemli etkileri olmaktadır.

2. Rayleigh sayısının artışı ısı transferini üç kattan daha fazla arttırmaktadır.

3. Bor nanoparçacıkların su ile hacimsel karışım oranı arttıkça ısı transferi de \% 14'lere varan oranda artmaktadır. Ancak bu artış Rayleigh sayısına bağlı artışla kıyaslandığında daha düşük kalmaktadır.

4. Nanoparçacıkların sabit Rayleigh sayılarındaki hacimsel karıșım oranının artışı, akım şiddetinin bir miktar artmasına yol açarken ortam içerisindeki sıcaklık dağılımını çok fazla etkilememektedir.

5. Bor nanoparçacıkları bakır ve alüminyum oksit nanparçacıkları ile karşılaștırıldığında daha yüksek ISı transferi değerleri sağlamaktadır.

Geleneksel ısı aktarım akışkanı olarak kullanılan su yerine dünyadaki rezervlerinin büyük bir çoğunluğu ülkemizde bulunan ve stratejik bir öneme sahip bor nanoparçacıklarının belirli hacimsel karışım oranlarında su ile karıştırılması sonucu ortaya çıkan nanoakışkanın kapalı ortamlarda kullanımı, gerçekleşen isı transferini arttırmaktadır. Bu artış miktarı nanoakıșkanlarda nanoparçacık olarak kullanılan bakır ve alüminyum oksitten daha yüksek olmaktadır. Ancak birim fiyatlar açısından değerlendirildiğinde dezavantajlı görülen bor nanoparçacıkların dünya üzerinde sayılı bölgelerde bulunması ve ülkemiz açısından avantajları düşünüldüğünde gelișen teknolojiyle birlikte iyi bir alternatif olabileceği değerlendirilmektedir. Ayrıca nanoakışkanlarda görülen çökelme, topaklaşma ve zaman içerisinde termofiziksel özelliklerinin değișimi gibi parametrelerin deneylerle belirlenmesi sonucu ısı transfer oranlarının daha da artacağı öngörülmektedir. 


\section{Kaynakça}

[1] de Vahl Davis, G. 1983. Natural convection of air in a square cavity: a bench mark numerical solution. International Journal for numerical methods in fluids, 3(3), 249-264.

[2] Fusegi, T., Hyun, J. M., Kuwahara, K., \& Farouk, B. 1991. A numerical study of three-dimensional natural convection in a differentially heated cubical enclosure. International Journal of Heat and Mass Transfer, 34(6), 1543-1557.

[3] Barakos, G., Mitsoulis, E., \& Assimacopoulos, D. 0. 1994. Natural convection flow in a square cavity revisited: laminar and turbulent models with wall functions. International Journal for Numerical Methods in Fluids, 18(7), 695-719.

[4] Markatos, N. C., \& Pericleous, K. A. 1984. Laminar and turbulent natural convection in an enclosed cavity. International Journal of Heat and Mass Transfer, 27(5), 755-772.

[5] Choi, S.U.S ve Eastman, J. A. 1995. Enhancing thermal conductivity of fluids with nanoparticles. No ANL/MSD/CP-84938; CONF-951135-29. Argonne National Lab., IL (United States), 1-8.

[6] Tombal T.D., Özkan, Ş.G., Ünver K.İ., Osmanlığlu A.E. 2016. Bor bileşiklerinin özellikleri üretimi kullanımı ve nükleer reaktör teknolojisinde önemi, Bor Dergisi (2), 86-95.

[7] Żyła, G., Fal, J., Traciak, J., Gizowska, M., Perkowski, K. 2016. Huge thermal conductivity enhancement in boron nitride-ethylene glycol nanofluids, Materials Chemistry and Physics, 180, 250-255.

[8] Wan, Q., Jin, Y., Sun, P., Ding, Y. 2015. Tribological behaviour of a lubricant oil containing boron nitride nanoparticles, Procedia Engineering, 102, 10381045.

[9] Han, W., Wang, L., Zhang, R., Ge, C., Ma, Z., Yang, Y., Zhang, X. 2017. Water-dispersible boron nitride nanospheres with high thermal conductivity for heat-transfer nanofluids, European Journal of Inorganic Chemistry, (46), 5466-5474.

[10] Salles, V., Bernard, S., Chiriac, R., Miele, P. 2012. Structural and thermal properties of boron nitride nanoparticles, Journal of the European Ceramic Society, 32(9), 1867-1871.

[11] Zhi, C., Xu, Y., Bando, Y., Golberg, D. 2011. Highly thermo-conductive fluid with boron nitride nanofillers, ACS nano, 5(8), 6571-6577.

[12] Albanese, A., Tang, P. S., Chan, W. C. 2012. The effect of nanoparticle size, shape, and surface chemistry on biological systems, Annual Review of Biomedical Engineering, 14, 1-16.

[13] Kong, L., Sun, J., Bao, Y. 2017. Preparation, characterization and tribological mechanism of nanofluids, Rsc Advances, 7(21), 12599-12609

[14] Asadi, A., Aberoumand, S., Moradikazerouni, A., Pourfattah, F., Żyła, G., Estellé, P.,Mahian O., Wongwises S., Nguyen H.M., Arabkoohsar, A. 2019. Recent advances in preparation methods and thermophysical properties of oil-based nanofluids: A state-of-the-art review, Powder Technology. Volume 352, 15, 209-226.

[15] Buongiorno, J. 2006. Convective transport in nanofluids, Journal of Heat Transfer, 128(3), 240250 .
[16] Khanafer, K., Vafai, K., Lightstone, M. 2003. Buoyancy-driven heat transfer enhancement in a two-dimensional enclosure utilizing nanofluids, International Journal of Heat and Mass Transfer, 46(19), 3639-3653.

[17] Öğüt, E.B. 2009. Natural convection of water-based nanofluids in an inclined enclosure with a heat source, International Journal of Thermal Sciences, 48(11), 2063-2073.

[18] Öğüt, E.B. 2010. Eğik Kare Kapalı Bir Bölge İçindeki Su Bazlı Nanoakışkanların Doğal Taşınımla Isı Transferi, Isı Bilimi ve Tekniği Dergisi, 30(1), 23-33.

[19] Ben-Cheikh, N., Chamkha, A.J., Ben-Beya, B., Lili, T. 2013. Natural convection of water-based nanofluids in a square enclosure with non-uniform heating of the bottom Wall, Journal of Modern Physics, 4(02), 147.

[20] Ho, C.J., Chen, M.W., Li, Z.W. 2008. Numerical simulation of natural convection of nanofluid in a square enclosure: effects due to uncertainties of viscosity and thermal conductivity, International Journal of Heat and Mass Transfer, 51(17-18), 45064516.

[21] Ghasemi, B., Aminossadati, S. M., Raisi, A. 2011. Magnetic field effect on natural convection in a nanofluid-filled square enclosure, International Journal of Thermal Sciences, 50(9), 1748-1756.

[22] Ho, C.J., Liu, W.K., Chang, Y.S., Lin, C.C. 2010. Natural convection heat transfer of alumina-water nanofluid in vertical square enclosures: an experimental study, International Journal of Thermal Sciences, 49(8), 1345-1353.

[23] Abu-Nada, E., Oztop, H.F. 2009. Effects of inclination angle on natural convection in enclosures filled with $\mathrm{Cu}$-water nanofluid, International Journal of Heat and Fluid Flow, 30(4), 669-678.

[24] Aminossadati, S.M., Ghasemi, B. 2009. Natural convection cooling of a localised heat source at the bottom of a nanofluid-filled enclosure, European Journal of Mechanics-B/Fluids, 28(5), 630-640,

[25] Oztop, H.F., Abu-Nada, E. 2008. Numerical study of natural convection in partially heated rectangular enclosures filled with nanofluids, International journal of heat and fluid flow, 29(5), 1326-1336.

[26] Jou, R.Y., Tzeng, S.C. 2006. Numerical research of nature convective heat transfer enhancement filled with nanofluids in rectangular enclosures, International Communications in Heat and Mass Transfer, 33(6), 727-736.

[27] Alloui, Z., Vasseur, P., Reggio, M. 2011. Natural convection of nanofluids in a shallow cavity heated from below, International journal of Thermal sciences, 50(3), 385-393.

[28] Abu-Nada, E., Masoud, Z., Oztop, H.F., Campo, A. 2010. Effect of nanofluid variable properties on natural convection in enclosures, International Journal of Thermal Sciences, 49(3), 479-491.

[29] Bouhalleb, M., Abbassi, H. 2015. Natural convection in an inclined rectangular enclosure filled by $\mathrm{CuO}-$ H2O nanofluid, with sinusoidal temperature distribution, International Journal of Hydrogen Energy, 40(39), 13676-13684.

[30] Alloui, Z., Guiet, J., Vasseur, P., Reggio, M. 2012. Natural convection of nanofluids in a shallow rectangular enclosure heated from the side, The 
Canadian Journal of Chemical Engineering, 90(1), 69-78,

[31] Mahmoudi, A.H., Pop, I., Shahi, M. 2012. Effect of magnetic field on natural convection in a triangular enclosure filled with nanofluid, International Journal of Thermal Sciences, 59, 126-140.

[32] Ghasemi, B., Aminossadati, S.M. 2010. Brownian motion of nanoparticles in a triangular enclosure with natural convection, International Journal of Thermal Sciences, 49(6), 931-940.

[33] Aminossadati, S.M., Ghasemi, B. 2011. Enhanced natural convection in an isosceles triangular enclosure filled with a nanofluid, Computers \& Mathematics with Applications, 61(7), 1739-1753.

[34] Selimefendigil, F., Öztop, H.F. 2014. MHD mixed convection of nanofluid filled partially heated triangular enclosure with a rotating adiabatic cylinder, Journal of the Taiwan Institute of Chemical Engineers, 45(5), 2150-2162.

[35] Sun, Q., Pop, I. 2011. Free convection in a triangle cavity filled with a porous medium saturated with nanofluids with flush mounted heater on the Wall, International Journal of Thermal Sciences, 50(11), 2141-2153.

[36] Saleh, H., Roslan, R., Hashim, I. 2011. Natural convection heat transfer in a nanofluid-filled trapezoidal enclosure, International Journal of Heat and Mass Transfer, 54(1-3), 194-201.

[37] Mahmoudi, A.H., Pop, I., Shahi, M., Talebi, F. 2013. MHD natural convection and entropy generation in a trapezoidal enclosure using $\mathrm{Cu}$-water nanofluid, Computers \& Fluids, 72, 46-62.

[38] Esfe, M.H., Arani, A.A.A., Yan, W.M., Ehteram, H., Aghaie, A., Afrand, M. 2016. Natural convection in a trapezoidal enclosure filled with carbon nanotubeEG-water nanofluid, International Journal of Heat and Mass Transfer, 92, 76-82.

[39] Bondareva, N.S., Sheremet, M.A., Pop, I. 2015 Magnetic field effect on the unsteady natural convection in a right-angle trapezoidal cavity filled with a nanofluid: Buongiorno's mathematical model, International Journal of Numerical Methods for Heat \& Fluid Flow, 25(8), 1924-1946.

[40] Nasrin, R., Parvin, S. 2012. Investigation of buoyancydriven flow and heat transfer in a trapezoidal cavity filled with water- $\mathrm{Cu}$ nanofluid, International Communications in Heat and Mass Transfer, 39(2), 270-274.

[41] Miroshnichenko, I.V., Sheremet, M.A., Oztop, H.F., AlSalem, K. 2016. MHD natural convection in a partially open trapezoidal cavity filled with a nanofluid, International Journal of Mechanical Sciences, 119, 294-302.

[42] Soleimani, S., Sheikholeslami, M., Ganji, D.D., GorjiBandpay, M. 2012. Natural convection heat transfer in a nanofluid filled semi-annulus enclosure, International Communications in Heat and Mass Transfer, 39(4), 565-574.

[43] Sheikholeslami, M., Ellahi, R., Hassan, M., Soleimani, S. 2014. A study of natural convection heat transfer in a nanofluid filled enclosure with elliptic inner cylinder, International Journal of Numerical Methods for Heat \& Fluid Flow, 24(8), 1906-1927.

[44] Al-Zamily, A.M.J. 2014. Effect of magnetic field on natural convection in a nanofluid-filled semi-circular enclosure with heat flux source, Computers \& Fluids, 103, 71-85.

[45] Ali, M., Zeitoun, O., Almotairi, S. 2013. Natural convection heat transfer inside vertical circular enclosure filled with water-based $\mathrm{Al} 2 \mathrm{O3}$ nanofluids, International Journal of Thermal Sciences, 63, 115-124.

[46] Maxwell, J.C. 1873. A treatise on electricity and magnetism(Vol. 1), Oxford: Clarendon Press,

[47] Brinkman, H.C. 1952. The viscosity of concentrated suspensions and solutions, The Journal of Chemical Physics, 20(4), 571-571.

[48] Patankar, S. V. 1980. Numerical Heat Transfer and Fluid Flow, McGraw Hill, New York.

\section{Semboller Dizini (Nomenclature)}

$c_{p} \quad$ özgül ısı (J/kg.K)

g yerçekimi ivmesi $\left(\mathrm{m} / \mathrm{s}^{2}\right)$

H kapalı ortamın yüksekliği

k ısı iletim katsayısı (W/m.K)

L kapalı ortamın uzunluğu (m)

$\mathrm{Nu} \quad$ Nusselt sayısı

$\overline{\mathrm{Nu}} \quad$ ortalama Nusselt sayısı

p, P basınç $\left(\mathrm{N} / \mathrm{m}^{2}\right)$, boyutsuz basınç

Pr Prandtl sayısı, $v_{f} / \alpha_{f}$

Ra Rayleigh sayısı, $g \beta_{f}\left(T_{h}-T_{c}\right) L^{3} / v_{f} \alpha_{f}$

T sicaklık (K)

u, U yatay hız bileşeni, boyutsuz yatay hız bileşeni

v, V düşey hız bileşeni, boyutsuz düşey hız bileşeni

$\mathrm{x}, \mathrm{X}$ yatay koordinat, boyutsuz yatay koordinat

$\mathrm{y}, \mathrm{Y}$ düşey koordinat, boyutsuz düşey koordinat

\section{Yunan Harfleri (Greek Letters)}

$\alpha \quad$ isı yayılım katsayısı $\left(\mathrm{m}^{2} / \mathrm{s}\right)$

$\beta \quad$ hacimsel genleşme katsayısı (1/K)

$\phi \quad$ hacimsel karışım oranı

$\varphi \quad$ bağımlı değişken

$\psi \quad$ akım fonksiyonu

$\mu \quad$ dinamik viskozite $(\mathrm{kg} / \mathrm{s} . \mathrm{m})$

$v \quad$ kinematik viskozite $\left(\mathrm{m}^{2} / \mathrm{s}\right)$ 
DEÜ FMD 22(66), 701-714, 2020

$\rho \quad$ akışkan yoğunluğu $\left(\mathrm{kg} / \mathrm{m}^{3}\right)$

$\theta \quad$ boyutsuz sıcaklık

İndisler (Subscripts)

c düşük sıcaklık

f ana akışkan

h yüksek sıcaklık

nf nanoakışkan

p nanoparçacık 